\title{
Tuning of Finite Element Models of Multi-Girder Composite Structures
}

\author{
Elena Mola ${ }^{1}$, Murathan Ahmet Paksoy ${ }^{1}$, Giovanni Rebecchi ${ }^{1}$, Matteo Scaccabarozzi ${ }^{2}$, Marta \\ Berardengo $^{2}$ \\ 1 ECSD Srl, Via Goldoni, 22 - 20129 Milano \\ 2 Politecnico di Milano, Dipartimento di Meccanica, via La Masa 1, Milan, Italy. \\ e-mail: elena.mola@ecsd.it
}

\begin{abstract}
Dynamic load testing is an important part of the acceptance process for new bridges in Italy. This paper is an overview of a part of a field-testing program carried out to investigate the dynamic properties of the five main new viaducts along Brescia-Milano highway (BreBeMi) before their operation. Among them, the focus of the paper is on the Muzza Bridge and the VX1 Bridge: they are examples of continuous multi-girder composite structures. VX01 Bridge has a total length of $112 \mathrm{~m}$ with three continuous spans while Muzza spans approximately $80 \mathrm{~m}$ with a significant skew angle. Structural analysis was performed with the commercial FE software named Midas Gen. Modal parameters were obtained from experimental testing and were then employed in the calibration of the numerical models. The experimental evaluation of the performances of bridges proves very advantageous since it provides a benchmark for the validation of the numerical simulations, which often exhibit an inherent uncertainty. The presence of simplifications and assumptions in the numerical analysis may lead to results that don't accurately predict the service life conditions of the bridge. In this case study, a comparative discussion of experimental results and numerical predictions is carried out with reference to the two different, seismic isolated, highway bridges mentioned above, both of which were tested using both environmental excitation and forcing: a large set of data was thus collected and an extensive model tuning activity could be carried out, allowing a thorough sensitivity analysis of a number of modelling parameters. The effects of different assumptions used when modelling some peculiar features of composite bridges, such as diaphragms, stiffeners, skew angle, expansion joints, rubber bearings etc., on the prediction of the dynamic properties of the composite viaducts, were investigated. At the same time, a comparison between the experimental results provided by ambient and forced vibration test results was carried out, based on their effectiveness in providing a reliable and useful benchmark for model tuning. Some conclusive suggestions based on the case study are finally addressed to structural engineers needing to set up an efficient procedure to perform similar tests and computer analyses.
\end{abstract}

KEYWORDS: operational modal analysis, experimental modal analysis, finite element model, model tuning

\section{INTRODUCTION}

The new highway called BreBeMi, connecting the Northern Italian cities of Bergamo, Brescia and Milano, was opened to traffic in July 2014 . The highway is $65 \mathrm{~km}$ long and includes five large bridges: three of them are r.c. hollow core girder bridges, two of them are composite steel-concrete girder bridges. In Italy, the latest version of the Italian Building Code, i.e. 'NTC 2008', requires that, before bridges considered 'strategically relevant' can be opened to the public, some dynamic tests be carried out, in addition to the traditional static load tests. In the case of the BreBeMi highway, the five above mentioned bridges were considered 'strategically relevant' by the Owner and by the design validator, so that a full experimental campaign was designed and carried out on all of them.

In particular, for design and construction validation purposes, NTC 2008 requires for the first experimentally identified modal frequency to be 'comparable' to the first modal frequency derived from 'the analysis'. Such a generic sentence does not offer proper guidance to the project validator, to the structural designer and to the designer of the experimental tests. In this regard, the current Italian code is lacking, which calls for the designers, analys ts and validators to merge their respective skills in order to draft testing protocols able to provide a larger set of data than the one strictly required by the normative documents.

In fact, in order to properly carry out a meaningful comparison between the dynamic properties of a flyover as derived by an eigenvalue analysis of a FE model of the bridge and the dynamic properties as experimentally identified by means of Operational or Experimental Modal Analysis, it is necessary to extend the comparison not only to the 'first natural frequency', but to a significant number of natural frequencies and, most of all, to the related mode shapes. 
In fact, when a good match, not only between the natural frequencies, but also between the mode shapes is attained, a much better validation for the model is provided and a deeper insight into the correspondence between the design assumptions and the as-built structure is guaranteed.

In this framework, it is easy to understand that a number of different, specialized skills are necessary when carrying out dynamic tests for design and construction validation purposes: on one hand, the measured data and the data treatment procedures adopted to experimentally estimate the dynamic properties must be accurate and efficient, on the other hand, the numerical counterpart, i.e. the parameters and assumptions used when implementing the finite element model and the structural analysis techniques used to derive the dynamic properties, must be refined and accurate enough to provide a reliable numerical benchmark for the experimental data.

Since every numerical model is affected by a degree of uncertainty, though, due to the inherent statistical nature of the material properties, boundary conditions, loads, mass distribution, computational errors, etc., there are a number of modelling parameters that affect the results. It is usually necessary to carry out a parameter sensitivity test on most numerical models in order to determine how strongly the variation of some of the basic or most critical modelling assumptions affect the results. Such sensitivity tests gauge the reliability and robustness of the model, which is very useful for the designer to determine, but most of the time they remain a purely numerical simulation exercise that has no experimental benchmark. Having an external database to use as a benchmark for model validation is thus a very rare but very useful opportunity.

When dynamic tests are carried out, they do provide this set of data: when comparing the results of a numerical analysis to the results of OMA or EMA tests, a very useful model validation tool thus becomes available to the analyst.

The comparison between the experimental and numerical results, in fact, provides an invaluable wealth of information about the behaviour of the as-built structure vs the prediction of the model: when the initial match between the numerical and experimental results is carried out, a model tuning or updating process can be started, which in the end will allow a refinement of the numerical analysis model and the reduction of the inherent uncertainty in the definition of some of its parameters.

It must be clarified that a correct and useful model tuning procedure cannot be carried out by simply varying all the possible parameters without engineering judgment in order to try and match the experimental data set in the best possible way: this kind of approach is totally useless and even counterproductive.

On the other hand, the correct approach to model tuning takes into account that the error between the measured data and the numerical prediction can be due to a vast number of reasons, not last inadequacies and/or mistakes in the construction process, which must be properly highlighted by the testing activity, whose main purpose in in fact to provide insight on the quality of the constructed structure. If, even after a refinement of the numerical model, a significant mismatch between the predictions and the results remains, then a red flag must be raised and some other reasons for said mismatch must be found, not in the numerical model but in the construction process or in the tests themselves, because even the data measurement and treatment process is affected by uncertainties or mistakes.

In the following, the model tuning activity carried out on the numerical models of two of the five main bridges of the BreBeMi highway will be presented. The testing and modelling activities carried out on the other bridges is thoroughly reported in (Cigada et al, 2013). The two chosen bridges, named Muzza and VX01, have composite steel concrete decks and were analysed by means of the commercial structural analysis software Midas Gen v.13.

Both bridges were then tested: both Operational and Experimental Modal Analysis were carried out and the results of the two sets of tests were used as a benchmark to tune the models. In the following paragraphs, at first, a description of the bridges will be provided, followed by a detailed description of the numerical models. The experimental results will then be presented and compared to the numerical ones. In the final section, the model tuning activity will be discussed and the results from the tuned model will be compared to the experimental ones, highlighting the improvement in the match between the two data sets.

\section{DESCRIPTION OF THE STRUCTURES}

\section{VX01 Bridge}

The new VX bridge was constructed between 2011 and 2013 as an essential link for the motorway between Brescia and Milano and is now in operational phase. The bridge consists of 3 spans for a total length of $112 \mathrm{~m}$, with the longest span, $44 \mathrm{~m}$ long, in the middle, and two $33 \mathrm{~m}$ long side spans, as represented in Fig. 1. The deck is $17.05 \mathrm{~m}$ wide including the $0.7 \mathrm{~m}$ wide curbs to support the safety barriers. The three-span composite multi-girder bridge consists of four continuous IPE girders with $180 \mathrm{~cm}$ height and a $30 \mathrm{~cm}$ thick concrete deck. The girders and deck are connected by shear studs to achieve composite section behaviour. Each girder is spaced 3.7m (center to center), as shown in Fig. 2. Lateral and torsional restraints to the girders are achieved at the supports and by means of intermediate transverse diaphragm beams along the bridge length.

The bridge is supported at the midspan by two wall-type piers and at the ends by abutments. High damping rubber bearing pads are used as supports, between the deck and the piers. On each pier, four elastomeric pads are placed under each longitudinal beam. The technical properties of the rubber pads are summarized in Tab. 1. The bridge is equipped 
with expansion joints at two abutments. The expansion joint is designed to allow relative displacements up to $20 \mathrm{~cm}$ only in the longitudinal direction of the bridge.

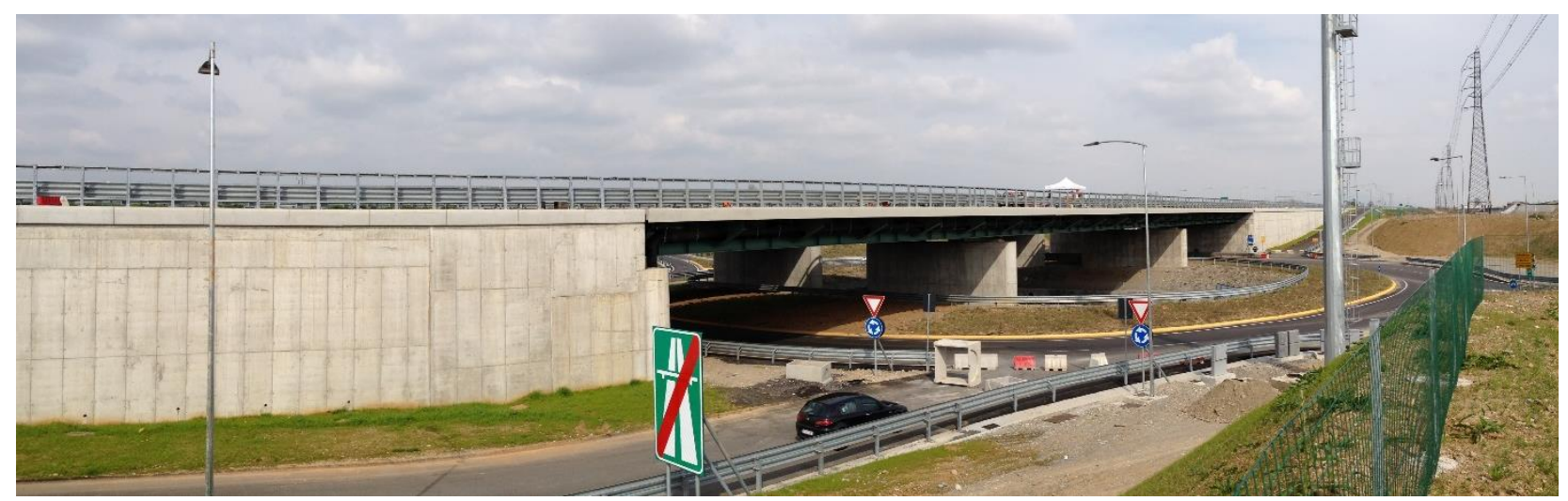

Figure 1: VX Bridge: view
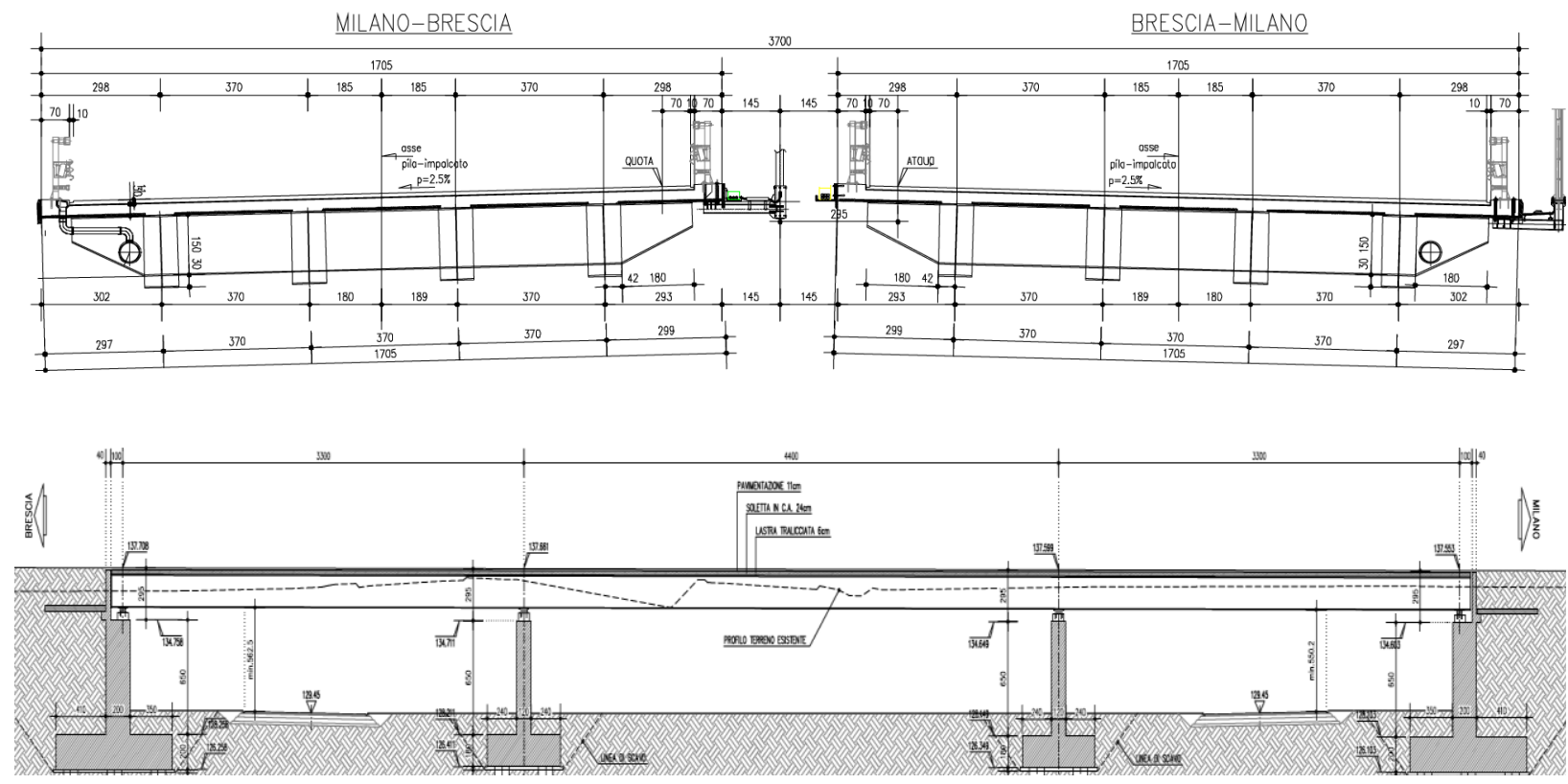

Figure 2: VX Bridge, (a) cross section (b) longitudinal section

Table 1: Technical details of the elastomeric isolators

\begin{tabular}{|c|c|c|c|c|c|}
\hline & Diameter $(\mathbf{m m})$ & $\begin{array}{c}\mathbf{G}_{\text {rubber }} \\
(\mathbf{M P a})\end{array}$ & $\Delta \mathbf{( m m})$ & $\mathbf{K}_{\mathbf{h}}(\mathbf{k N} / \mathbf{m m})$ & $\mathbf{K}_{\mathbf{v}}(\mathbf{k N} / \mathbf{m m})$ \\
\hline Abutment(Milano) & 400 & 0.8 & 200 & 1.01 & 912 \\
\hline Abutment(Brescia) & 400 & 0.8 & 200 & 1.01 & 912 \\
\hline Pile & 550 & 0.8 & 200 & 1.81 & 1683 \\
\hline
\end{tabular}

\section{MUZZA Bridge}

The new Muzza bridge consists of two skewed, parallel sections, one for the northern and one for the southern way. The construction of the bridge was completed in 2013 and the flyover now serves as an important part of the BreBeMi motorway between Brescia and Milano. The bridge consists of a single span with a total length of $80 \mathrm{~m}$, as represented in Fig. 4. The deck is $17.05 \mathrm{~m}$ wide including the $0.7 \mathrm{~m}$ wide curbs to support the safety barriers. The deck consists of four continuous IPE girders with a height of $170 \mathrm{~cm}$, and of top a concrete slab, approximately $28 \mathrm{~cm}$ thick. The girders and deck are connected by shear studs to achieve composite section behaviour. Each girder is spaced $4.0 \mathrm{~m}$ (center to center). Three struts for each girder provide the load transfer to the steel elements located below. Lateral and torsional restraints to the girders are achieved at the supports and by means of intermediate transverse bracings along the bridge length. 


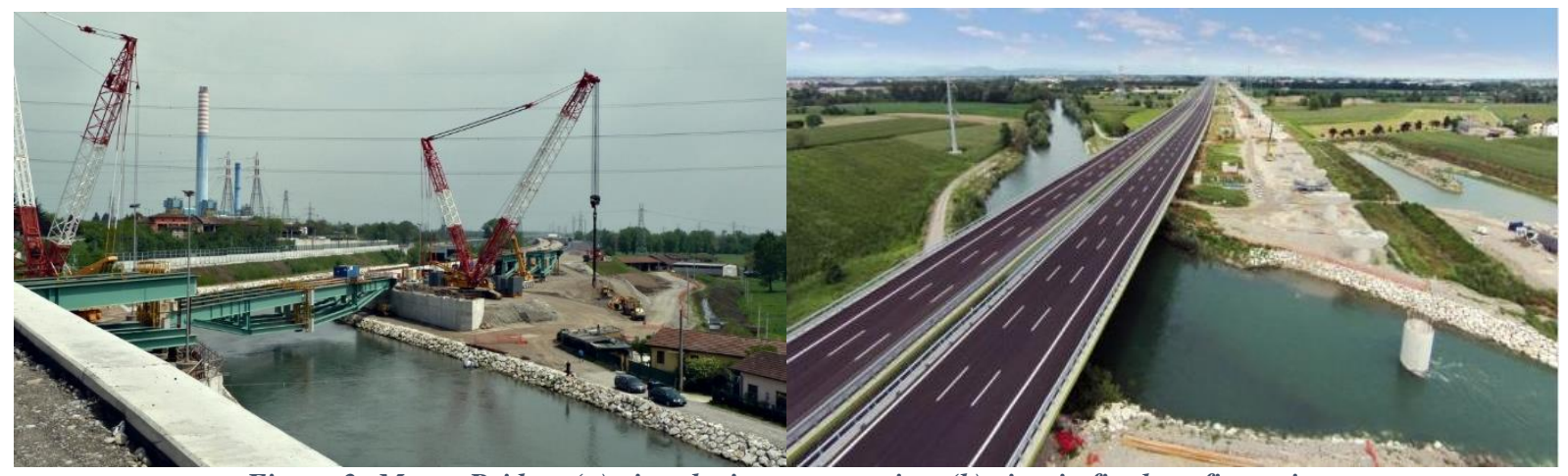

Figure 3: Muzza Bridge, (a) view during construction, (b) view in final configuration
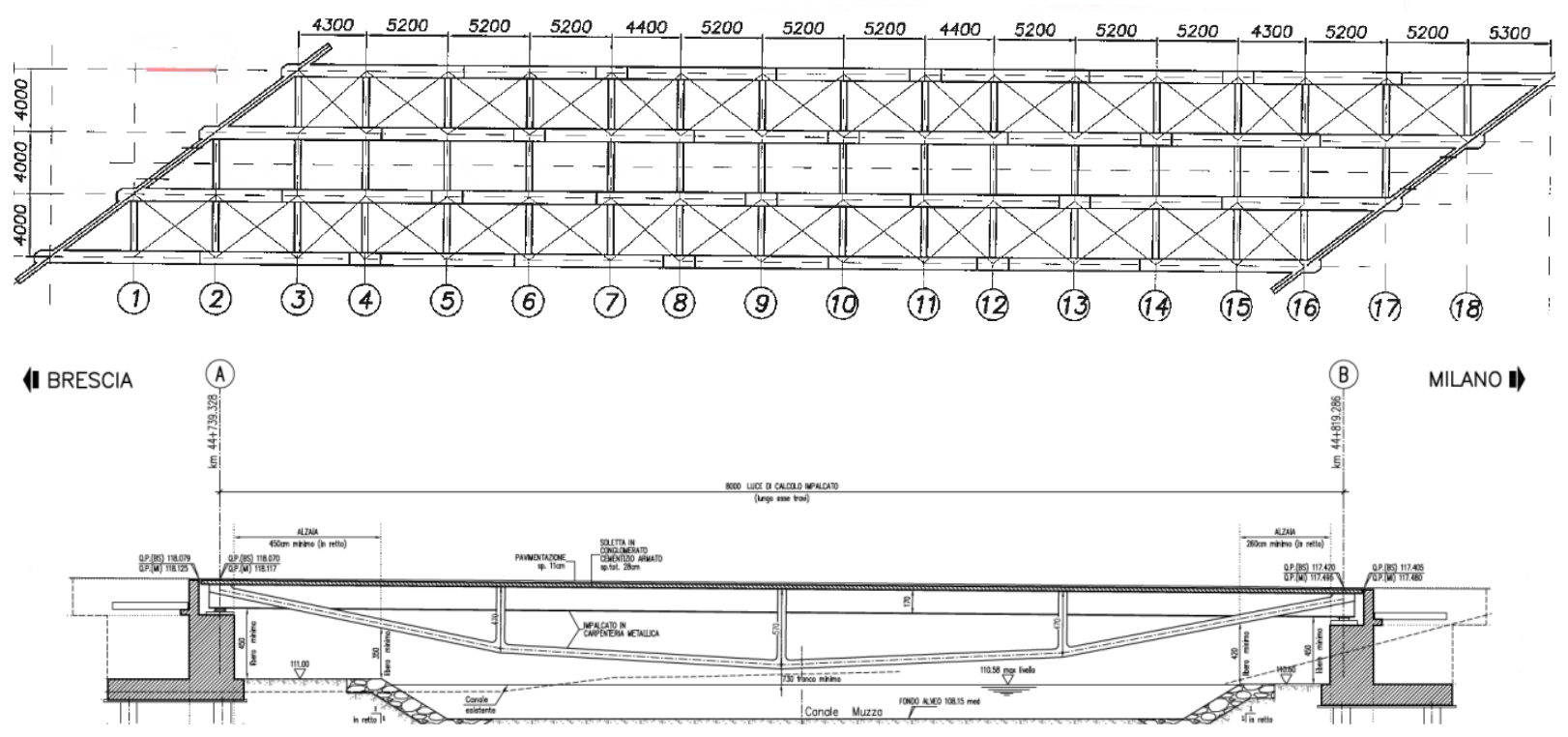

Figure 4: Muzza Bridge, (a) plan view (b) longitudinal section.

The bridge is supported at two ends by reinforced concrete abutments. The bridge superstructure is supported on the abutments by using high damping rubber bearing pads. The technical properties of the rubber pads are summarized in Tab. 2. The bridge is equipped with expansion joints at two abutments. The joint is designed to allow relative displacements up to $20 \mathrm{~cm}$ only in the longitudinal direction of the bridge.

Table 2: Technical details of the elastomeric isolators

\begin{tabular}{|c|c|c|c|c|c|}
\hline & Diameter $(\mathbf{m m})$ & $\mathbf{G}_{\text {rubber }}(\mathbf{M P a})$ & $\boldsymbol{\Delta} \mathbf{( m m})$ & $\mathbf{K}_{\mathbf{h}}(\mathbf{k N} / \mathbf{m m})$ & $\left.\mathbf{K}_{\mathbf{v}} \mathbf{( k N / m m}\right)$ \\
\hline Abutment(Milano) & 500 & 1.4 & 150 & 3.52 & 2406 \\
\hline Abutment(Brescia) & 500 & 1.4 & 150 & 3.52 & 2406 \\
\hline
\end{tabular}

\section{NUMERICAL ANALYSIS: STRUCTURAL MODEL AND ENGINEERING ASSUMPTIONS}

The models of the two bridges were developed in order to provide the estimate of the modal properties to be compared to the experimentally derived results. In principle, the main dynamics of interest is that of the deck, in normal service life condition, i.e. in the low vibration field. The presence of the elastomeric isolators almost completely disconnects the dynamic behaviour of the deck from that of the substructure, i.e. piers and foundations: the much lower lateral stiffness of the rubber bearing supports can be assumed as a low stiffness spring working in series with a spring with a much higher stiffness, representing the piers. In order to gauge the contribution of the piers to the global dynamic, though, it was decided to include them in the modelling, to increase the accuracy of the model, even if, for practical purposes, the rubber bearings could be considered as directly restrained to the ground.

As for the deck, it is crucial to make wise modelling choices in order to replicate in the most accurate possible way the stiffness and the mass distribution, because these parameters strongly affect the estimate of the dynamic properties. 
A finite element model of composite decks can be developed in several ways. Simple models with large elements are quick to implement and solve but they may provide overly approximated results. Complex models with a fine mesh can yield more realistic results, at the cost of increased computational time. An ideal model yields accurate results with minimal computational time.

In the present case, the most common element types, i.e beams, trusses and shells, were used for modelling the global behaviour of the bridges. Special structural elements like springs and rigid connections were also employed in the models to provide the most accurate internal constraints and boundary conditions. In order to achieve the most efficient balance between computational time and accuracy, the analyst should decide on a good meshing size for the elements. In the present study, the mesh size is not governed by a variation in the geometry of the bridge along the longitudinal axis, as both of the bridges do not contain a curvature: the geometry remains constant along the length of the bridge. Of course the main factor to decide on the mesh size of the elements depends very much on the types of element used in modelling, and on their shape functions. For this reason, there is no general hand rule to fit the needs of an engineer. The meshing is a specific property of each individual model. In this specific case, it was also important to correctly locate the joints of the mesh where the accelerometers would be installed during the tests, or close enough. In this way, the local values of the mode shapes vectors derived by the model could be easily compared to those derived from the tests at the exact location of the sensors.

The difficulty presented by these bridges is the composite steel concrete structure of the deck: it is difficult to choose the best modelling technique to replicate the interaction between the two substructres, which in turns affects the dynamic properties. Different finite element modelling options used are shown in Fig.5 for VX and Muzza bridges. Model N.1 is an equivalent beam representation of the composite structure with an equivalent Poisson's ratio, mass density, and Young's modulus. In Model N. 2 of the bridge, two different layers of structural nodes were arranged to model the superstructure. The first layer of nodes were defined to create the plate elements representing the reinforced concrete deck and the second layer, below the first, was defined to represent the girders with beam elements. The plate elements used in the model have five degrees of freedom per node, whereas the steel girder elements have six degrees of freedom per node. A final model named Model 3 represents the entire superstructure by using only plate elements. Except for Model N.1, all the models are capable of capturing the effect of the offset between the center of gravity of the steel girder and the center of gravity of the deck slab. In Model N.3, the error induced by the incompatibility between the in-plane rotational degree of freedom and the drilling degree of freedom of plate elements was overcome by decreasing the mesh size.

In general, all of the three above-mentioned modelling options give reasonable results for the first mode of vibration but differ significantly in their ability to predict subsequent modes. The representation of composite action presented the first challenge in the construction of the finite element models. After the results of the experimental tests, though, a direct comparison between the modal parameters given by the different modelling options and those derived from the tests was carried out, as will be detailed in the following, in order to confirm the final choice of the most effective model.
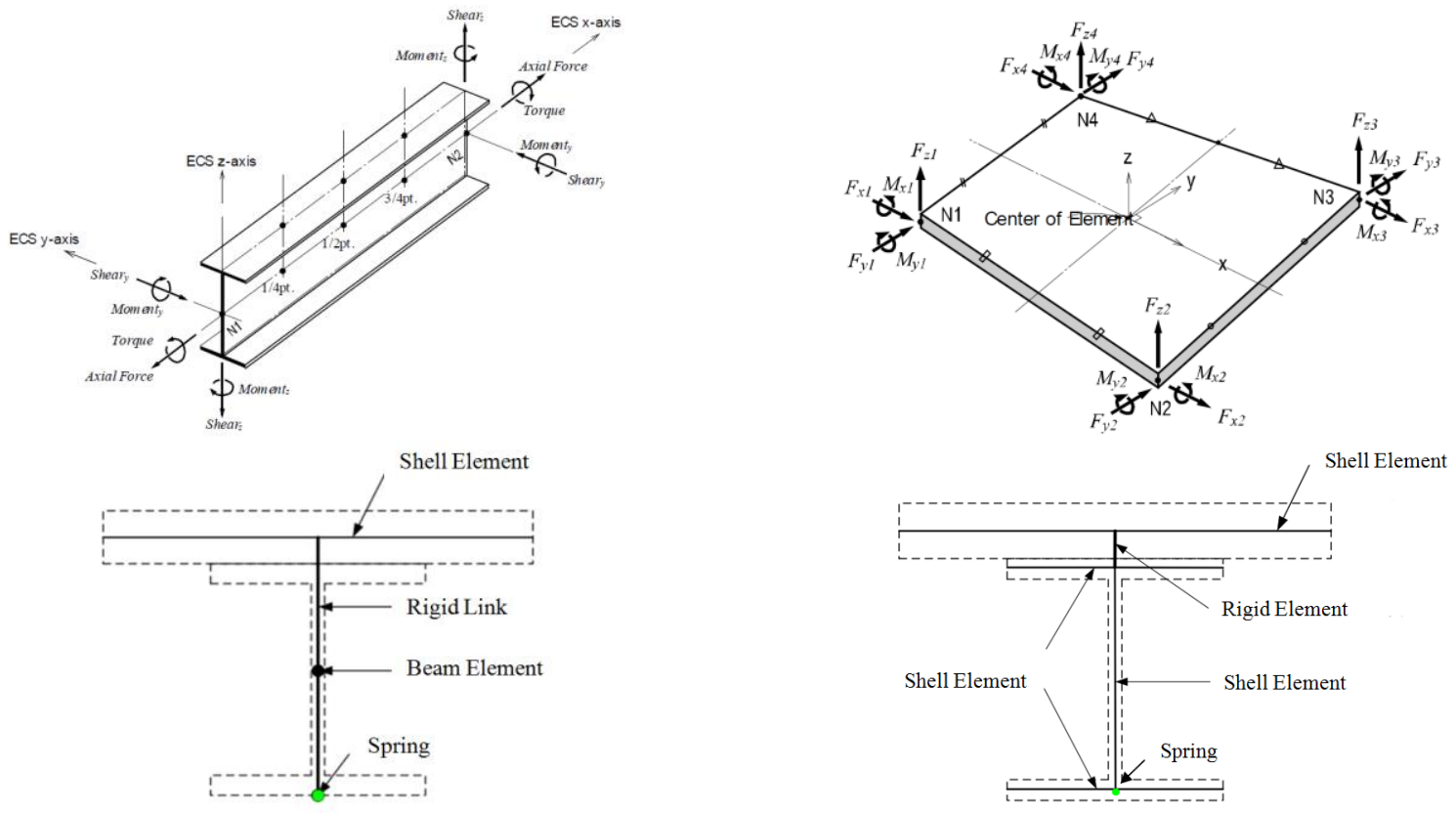

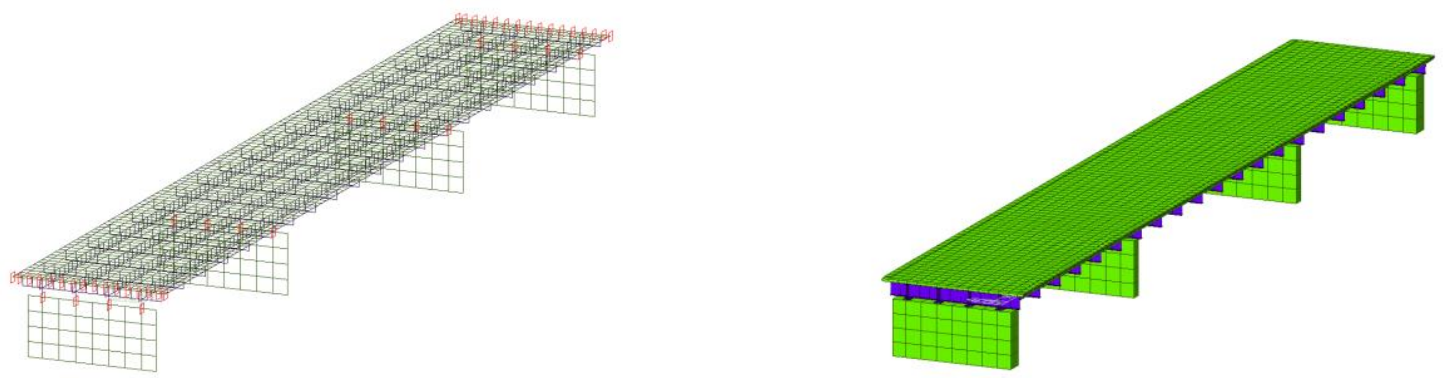

Figure 5. Superstructure idealization of VX bridge for Model 2 and Model 3

In order to correctly replicate the boundary conditions, the rubber bearing supports in both bridges were modelled by means of elastic links: the bearings exhibit a practically linear lateral displacement vs force behavior. The stiffness values provided by the producer and reported in Tab.1 and Tab.2 (for VX01 and for Muzza respectively) were assigned to the rigid links in the model.

Both the VX01 Bridge and the Muzza Bridge were designed to be equipped with expansion joints at the sides: these joints allow thermal deformations and also allow the larger, earthquake-induced relative displacements between the deck and the rest of the road to take place without inducing damage in the structural elements. The two bridges were equipped with peculiar side joints that allow longitudinal displacements to take place but restrain the transverse displacements. The correct boundary condition to represent the effects of this kind of joint in the low displacement field must thus be enforced by assigning the side elements of the bridge free ends longitudinally and restrained ends transversally, otherwise the predicted mode shapes will not be accurate.

The four main aspects mentioned above, i.e. composite section behaviour, isolating supports behaviour, presence of the sound barriers and of the lateral expansion joints, can be assumed as the main parameters affecting the estimate of the modal properties. In the following, their influence will be shown when comparing the numerical and experimental results.
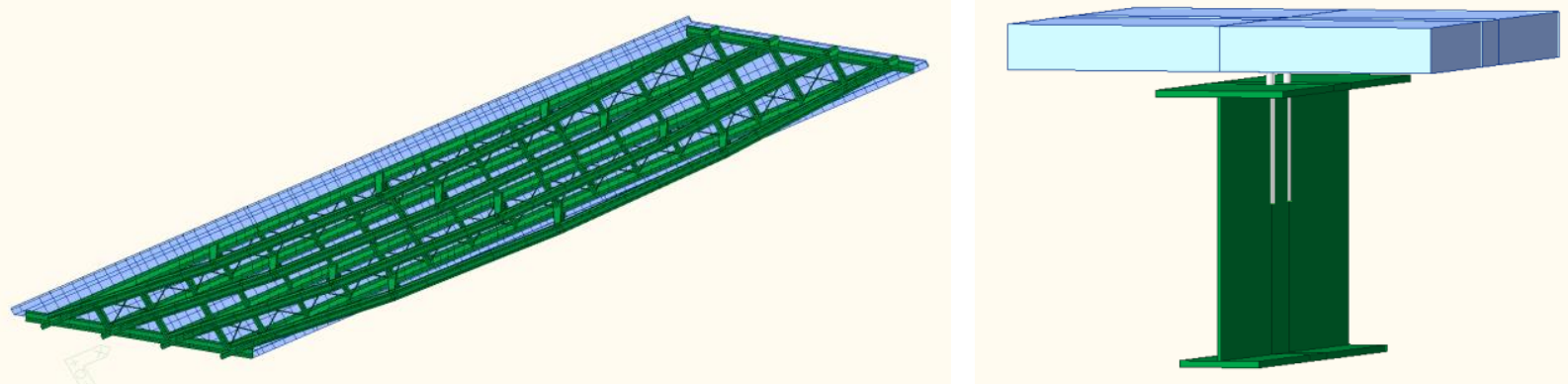

Figure 6: FE model of Muzza Bridge, (a) final model, (b) detail of the beam-slab connection

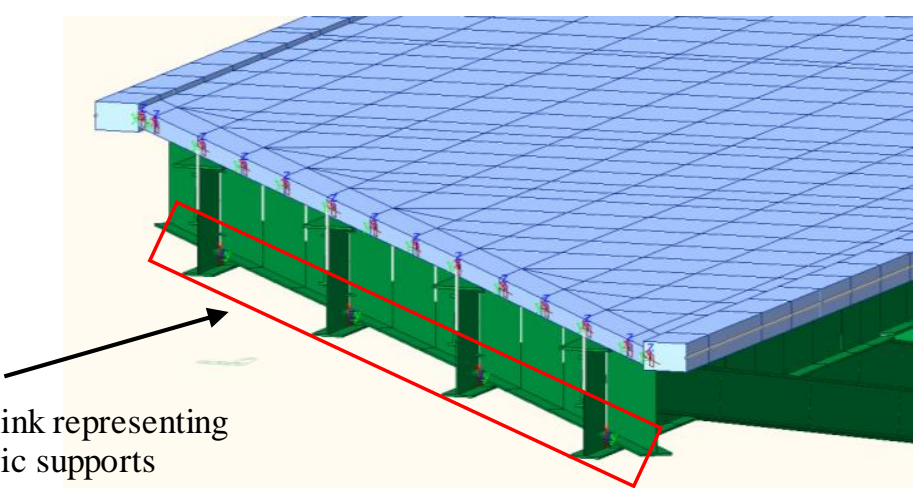
the elastomeric supports

Figure 7: FE model of Muzza Bridge, detail of the elastic link used to model the elastomeric supports

\section{EXPERIMENTAL CAMPAIGN}

The experimental campaign on the VX01 bridge consisted of OMA tests only. The one on the Muzza Bridge consisted of both OMA and EMA tests, with vertical and horizontal forcing, transverse to the longitudinal axis of the bridge. 
For each test, the measurement set up consisted in measurement points in the vertical direction, transversal direction and longitudinal direction. The transducers are seismic low noise piezoelectric accelerometers conditioned and recorded using a 24 bit A/D converter with built in anti-aliasing filters. The location of the sensors is reported in Fig. 8.

In order to obtain robust spectral quantities estimates in the OMA tests, the system was left recording on the bridges for 8 hours. For the EMA tests on the Muzza Bridge, both a vertical forcing and a horizontal one were provided. The vertical and horizontal forcing point was located in the center of the bridge, both longitudinally and in the transverse direction.
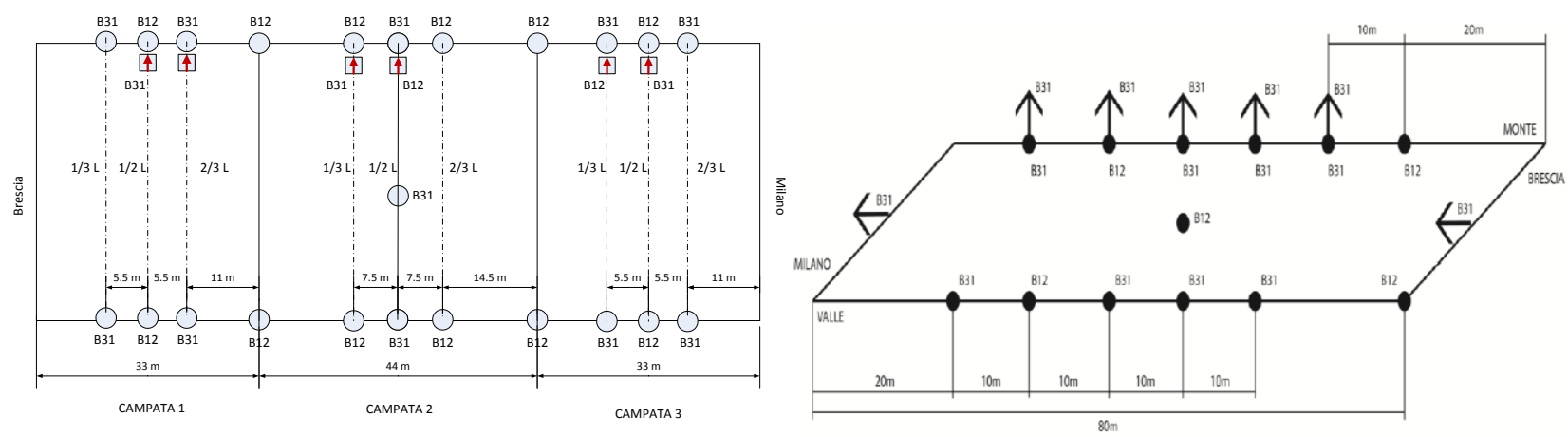

Figure 8: location of the sensors, (a) VX01 Bridge, (b) Muzza Bridge

The accelerations were analyzed using the Polyreference Least Square Frequency Domain algorithm (Peeters et al., 2005, Peeters et al., 2004). The identified modal frequencies and dampings are reported in Tab.3, for the OMA tests on VX01 Bridge and for the OMA and EMA tests on the Muzza Bridge.
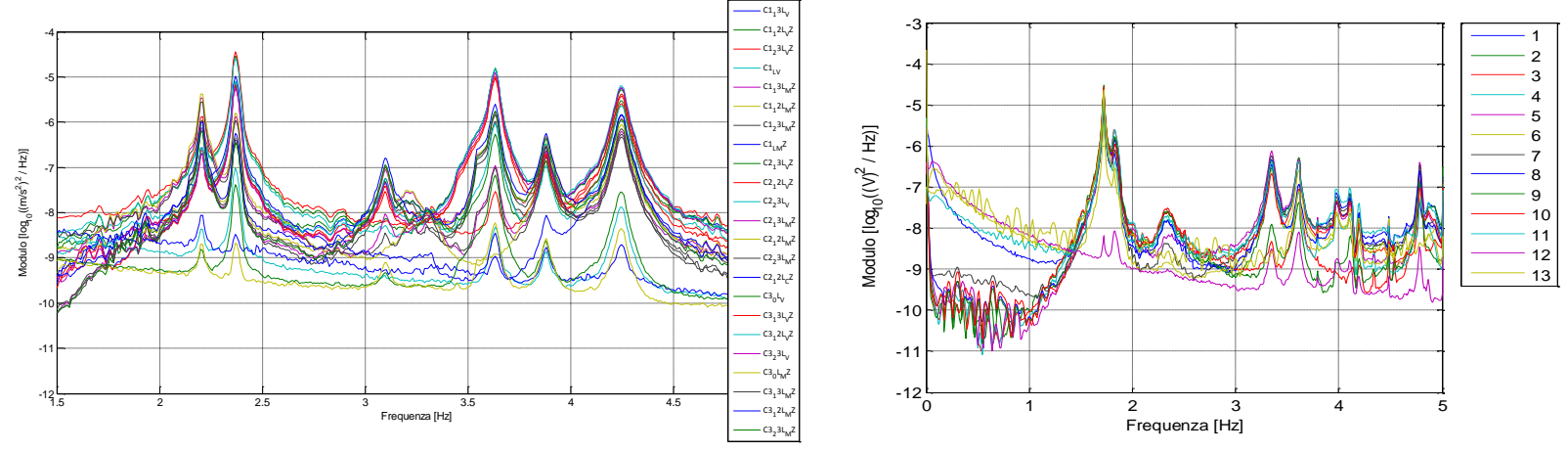

Figure 9: PSD plots of (a) vertical channels during the OMA test on VX01, (b) vertical channels during the OMA test on Muzza Bridge

In Fig.9, the Power Spectral Densities for the measured signals, during the OMA tests for VX01 and for Muzza Bridge, are represented. The peaks highlighting the first natural frequencies are clearly visible in both cases.

Table 3: Modal frequencies identified from OMA test on VX01 and from OMA and EMA tests on Muzza

\begin{tabular}{|c|c|c|c|c|c|}
\hline \multicolumn{2}{|c|}{ VX01 OMA } & \multicolumn{2}{c|}{ MUZZA OMA } & \multicolumn{2}{c|}{ MUZZA EMA } \\
\hline $\mathrm{F}[\mathrm{Hz}]$ & $\xi[\%]$ & $\mathrm{F}[\mathrm{Hz}]$ & $\xi[\%]$ & $\mathrm{F}[\mathrm{Hz}]$ & $\xi[\%]$ \\
\hline 2.20 & 0.48 & 1.72 & 0.38 & 1.72 & 0.42 \\
\hline 2.37 & 0.38 & 1.83 & 0.76 & 1.82 & 1.28 \\
\hline 3.10 & 0.71 & 2.34 & 2.5 & 2.28 & 2.28 \\
\hline
\end{tabular}

The results from the tests show consistency between the OMA and EMA identification methods. The experimental damping values are low for both bridges, which is compatible with the structural configuration and the low levels of vibration. The mode shapes corresponding to the identified modes will be presented in the following paragraph and directly compared to those provided by the numerical eigenvalue analysis.

\section{NUMERICAL AND EXPERIMENTAL RESULT COMPARISON}

As mentioned in the previous paragraph, the comparison between the experimentally derived frequencies and corresponding mode shapes and those yielded by the different models for each bridge allowed the initial phase of model tuning to be carried out. In Tab.4 and Tab.5, the measured flexural and torsional frequencies and mode shapes obtained from the experimental tests are compared with the analytical model results. As both bridges are completely isolated above the substructure, the comparison for the different modelling options was based on the obtained flexural and torsional responses. The translational response of these bridges is not strongly affected by how accurately the composite 
behaviour is captured. According to the results, both Model N.1 and Model N.3 appear to respond more flexibly than Model N.2. The comparison between the mode shapes of Model N.2 and Model N.3 also reveals that there is a switch between the flexural and torsional modes of the deck response. Instead, the line model fails to accurately estimate the response frequency of the bridges due to its inability of simulating the composite behaviour. In addition to these outcomes, Model N.1 also performs weakly in estimating the torsional response of the system because of the inaccurate representation of the torsional stiffness of the system. From what was observed in the present case studies, the best choice among the preliminary modelling options was thus confirmed to be Model N.2 based on the best match between experimental and numerical frequencies and mode shapes as discussed above.

Table 4: Comparison between numerical and experimental frequencies for VX01 and Muzza Bridges

\begin{tabular}{|c|c|c|c|c|c|c|c|}
\hline \multicolumn{4}{|c|}{$\mathbf{V X}$} & \multicolumn{4}{|c|}{ MUZZA } \\
\hline $\begin{array}{c}\text { Experimental } \\
\text { Modes }\end{array}$ & Model 1 & Model 2 & Model 3 & $\begin{array}{c}\text { Experimental } \\
\text { Modes }\end{array}$ & Model 1 & Model 2 & Model 3 \\
\hline 2.42 & f3: 1.62 & $\mathrm{f} 4: 2.40$ & $\mathrm{f} 4: 2.21$ & 1.72 & $\begin{array}{c}\text { Not } \\
\text { applicable }\end{array}$ & f4: 1.77 & $\mathrm{f} 4: 1.67$ \\
\hline 2.45 & f4: 1.63 & f5: 2.45 & f5: 2.31 & 1.82 & $\begin{array}{c}\text { Not } \\
\text { applicable }\end{array}$ & f5: 1.78 & f5: 1.69 \\
\hline 3.60 & f5: 2.72 & f6: 3.59 & f6: 3.27 & 2.29 & $\begin{array}{c}\text { Not } \\
\text { applicable }\end{array}$ & f6: 2.95 & f6: 2.68 \\
\hline 3.74 & f6: 3.01 & f7: 3.74 & f7: 3.59 & & $\begin{array}{c}\text { Not } \\
\text { applicable }\end{array}$ & $\mathrm{f} 7: 3.26$ & f7: 3.01 \\
\hline
\end{tabular}

Table 5: Comparison between numerical and experimental mode shapes for VX01

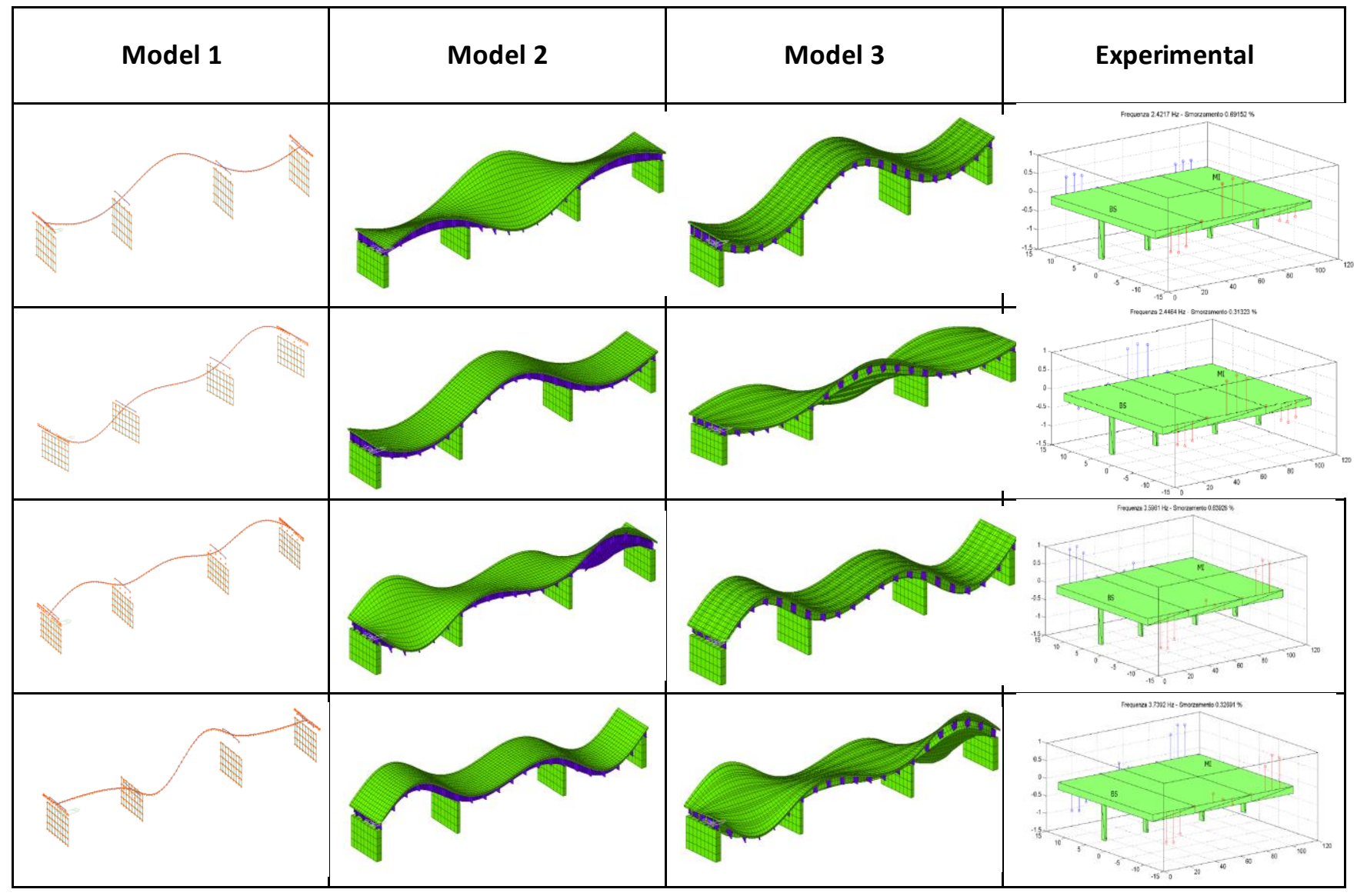

Table 6: Comparison between numerical and experimental mode shapes for Muzza

\begin{tabular}{|l|l|l|}
\hline Model 2 & Model 3 & Experimental \\
\hline
\end{tabular}




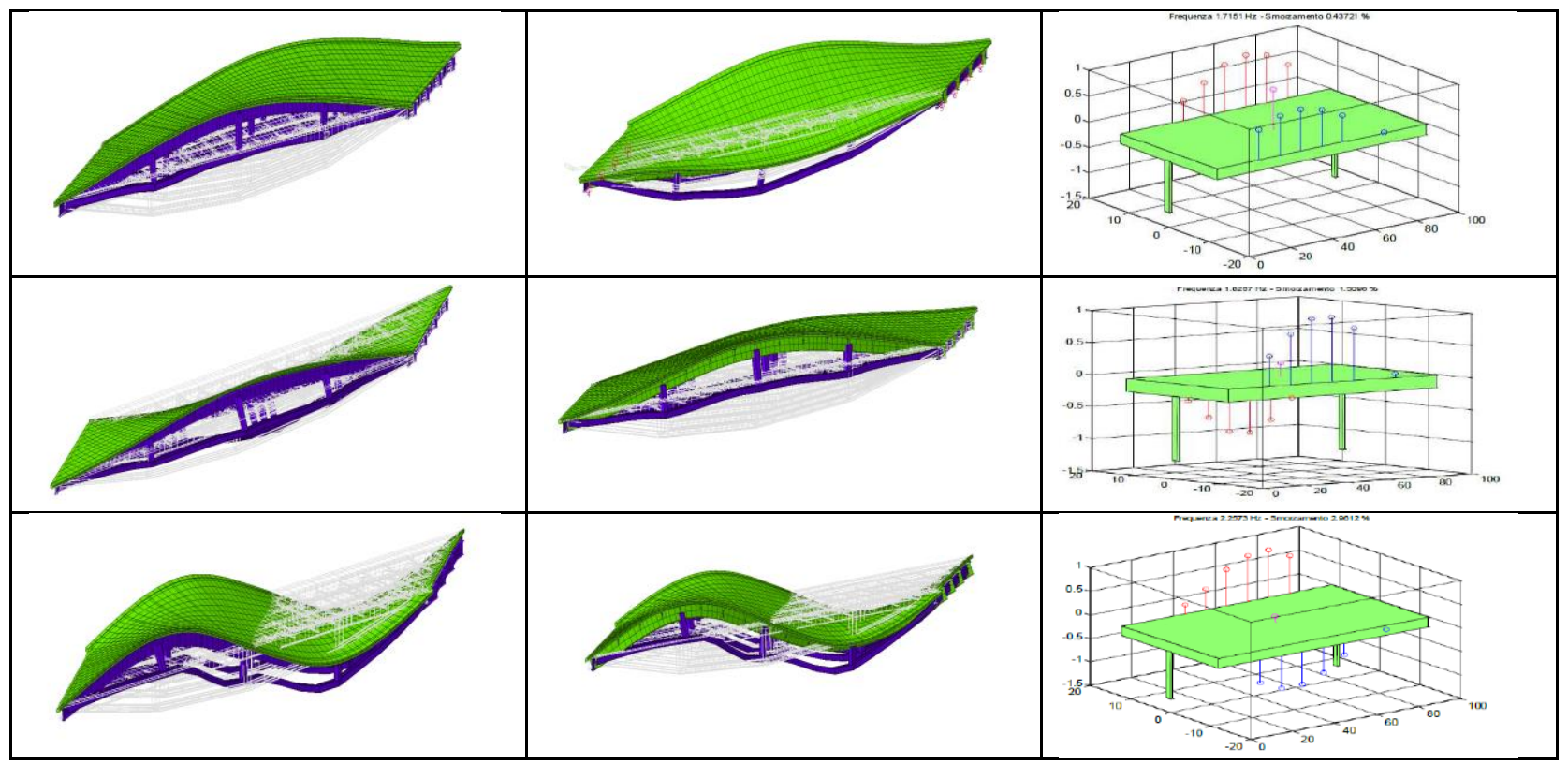

MODEL TUNING ACTIVITY

After choosing the best modelling option for the deck, model tuning activity was carried out: the effect of the previously mentioned critical parameters was investigated, i.e. rubber bearing, expansion joints, sound barriers, bracing connections.

For example, it was learnt that the effects of the presence of the joint device on the service life, low vibration level behaviour of the flyover is, in fact, non-negligible: the joints provide a lateral restraint that is us ually neglected in the design phase as it would get damaged under seismic excitation, but cannot be disregarded when determining the modal properties to be compared to the test result.

Also, the effects of the sound barriers were found out to be important in terms of additional dynamic mass to the global mass matrix of the system due to the light weight of the steel structure. In the present case studies their stiffness contribution was not found to be important but it needs further investigation for longer bridges.

The correct modelling of the lateral stiffness of the rubber bearings, as provided by the producers, turned out to be important to correctly catch the transverse and longitudinal components of the mode shapes. The elastomeric isolators are characterized by an effective shear modulus and this modulus is dependent on the shear strain experienced by the bearings. As the experimental eigenmode 3 of Muzza is sensitive to the characteristics of the bearing stiffness, the stable stiffness value assumed in modelling was verified through the eigenfrequency obtained from the experiment. On the other hand, by analysing the experimental mode shapes, the assumption that the dynamics of the piers and that of the deck are completely disconnected was confirmed: in this case, the substructure could have been excluded from the model with no significant error on the prediction of the mode shapes involving the decks and the supports.

Close examination of Tab. 7 and Tab. 8 reveals the importance of updating the sensitive parameters that affect the dynamic characteristics of the bridge. As the experimental test configuration and accelerometer locations corresponded to the initial model results, horizontal response of Muzza together with bending response was expected at frequency levels less than $2 \mathrm{~Hz}$. However, the translational mode coupled with a vertical bending was obtained at $2.3 \mathrm{~Hz}$, Fig. 10. While the initial model for Muzza predicts another bending mode just after the second torsional response, the tuned model predicts a translational mode with $2.3 \mathrm{~Hz}$ accurately. One must care when comparing eigenmodes for a system with different boundary conditions and concentrated mass distribution. According to Tab. 7, with the addition of expansion joints and sound barriers to VX model, the effect is more important than other parameters investigated. This change does not only create nearly identical mode shapes with different eigenfrequencies, but the Eigen mode shapes are completely different than the previously obtained ones.

Table 7: Frequency comparison between the experimentally measured values and FE model before and after model updating for $V X$

\begin{tabular}{|c|c|c|c|c|c|}
\hline $\begin{array}{c}\text { Mode nos. } \\
\text { named after } \\
\text { experiment }\end{array}$ & $\begin{array}{c}\text { Measured } \\
\text { Frequencies } \\
(\mathrm{Hz})\end{array}$ & Mode Shapes & $\begin{array}{c}\text { Initial Model } \\
(\mathrm{Hz})\end{array}$ & Mode Shapes & $\begin{array}{c}\text { Updated Model } \\
(\mathrm{Hz})\end{array}$ \\
\hline 1 & 2.20 & $\begin{array}{c}\text { Sliding } \\
\text { perpendicular to } \\
\text { bridge axis }\end{array}$ & 0.55 & $\begin{array}{c}\text { Sliding } \\
\text { perpendicular to } \\
\text { bridge axis }\end{array}$ & 2.20 \\
\hline 2 & 2.20 & Torsional response & 2.40 & Torsional response & 2.34 \\
\hline
\end{tabular}




\begin{tabular}{|c|c|c|c|c|c|}
\hline & & of deck & & of deck & \\
\hline 3 & 2.37 & $\begin{array}{c}\text { Vertical bending } \\
\text { of deck }\end{array}$ & 2.45 & $\begin{array}{c}\text { Vertical bending } \\
\text { of deck }\end{array}$ & 2.43 \\
\hline 4 & 3.10 & $\begin{array}{c}\text { Torsional response } \\
\text { of deck }\end{array}$ & 3.60 & $\begin{array}{c}\text { Torsional response } \\
\text { of deck }\end{array}$ & 3.51 \\
\hline
\end{tabular}

Table 8: Frequency comparison between the experimentally measured values and FE model before and after model updating for Muzza

\begin{tabular}{|c|c|c|c|c|c|}
\hline $\begin{array}{l}\text { Mode nos. } \\
\text { named after } \\
\text { experiment }\end{array}$ & $\begin{array}{c}\text { Measured } \\
\text { Frequencies } \\
(\mathrm{Hz}) \\
\end{array}$ & Mode Shapes & $\begin{array}{l}\text { Initial Model } \\
(\mathrm{Hz})\end{array}$ & Mode Shapes & $\begin{array}{l}\text { Updated Model } \\
(\mathrm{Hz})\end{array}$ \\
\hline & & $\begin{array}{l}\text { Sliding along the } \\
\text { bridge axis }\end{array}$ & 0.58 & & \\
\hline & & $\begin{array}{c}\text { Sliding } \\
\text { perpendicular to } \\
\text { bridge axis }\end{array}$ & 0.58 & & \\
\hline 1 & 1.72 & $\begin{array}{c}\text { Vertical bending } \\
\text { of deck }\end{array}$ & 1.77 & $\begin{array}{c}\text { Vertical bending } \\
\text { of deck }\end{array}$ & 1.75 \\
\hline 2 & 1.83 & $\begin{array}{c}\text { Torsional response } \\
\text { of deck }\end{array}$ & 1.78 & $\begin{array}{c}\text { Torsional response } \\
\text { of deck }\end{array}$ & 1.76 \\
\hline 3 & 2.34 & & & Sliding response & 2.30 \\
\hline
\end{tabular}
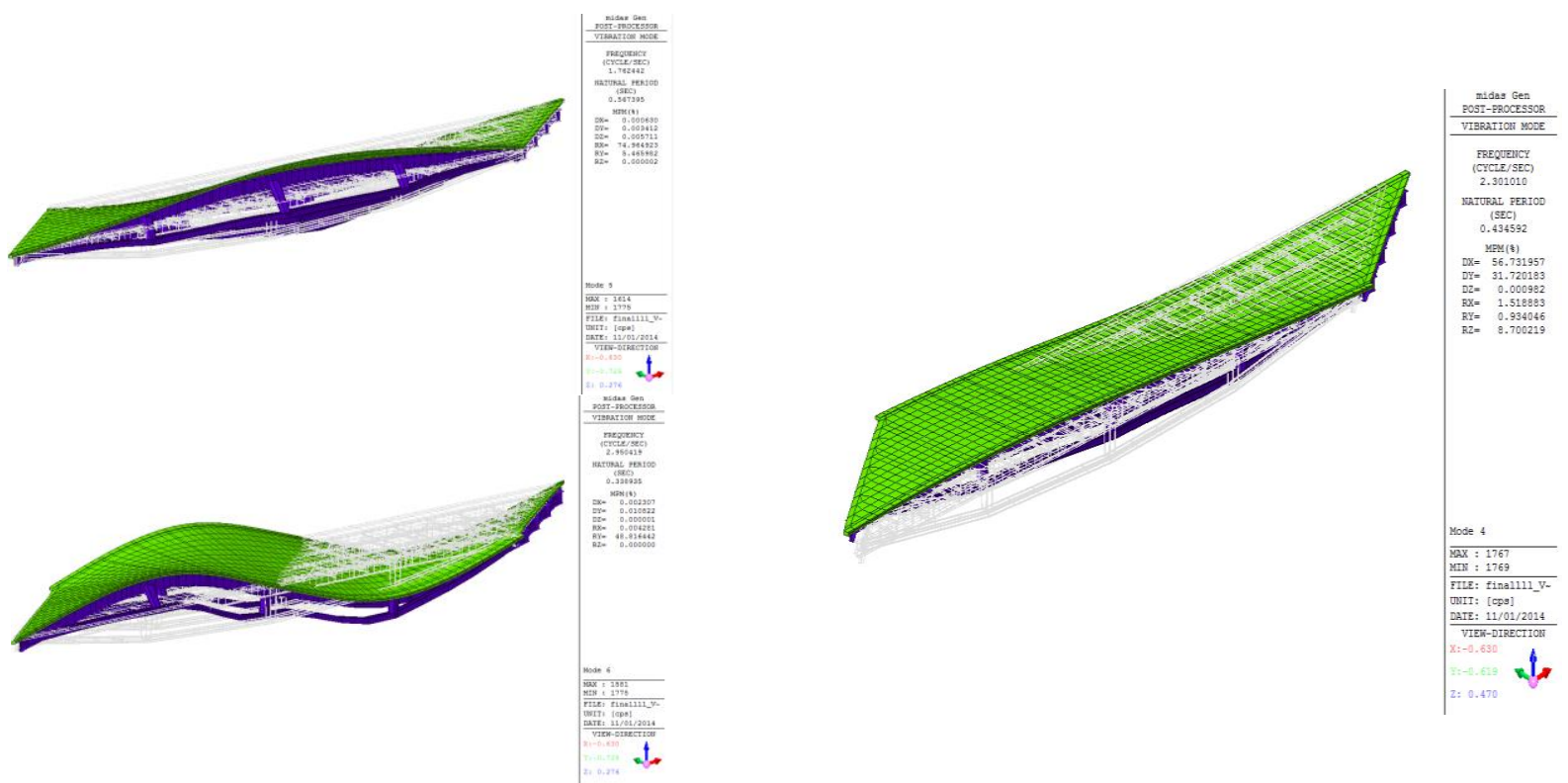

Figure 10: The dynamic response in the frequency range of 1.5-2.7 (a) before model update, (b) after model update

Table 9: Eigenmode shape comparison for VX

\begin{tabular}{|c|c|c|}
\hline $\begin{array}{c}\text { Mode nos. named after } \\
\text { experiment }\end{array}$ & Initial Model & \\
\hline 2 & & \\
\hline 3 & & \\
\hline
\end{tabular}




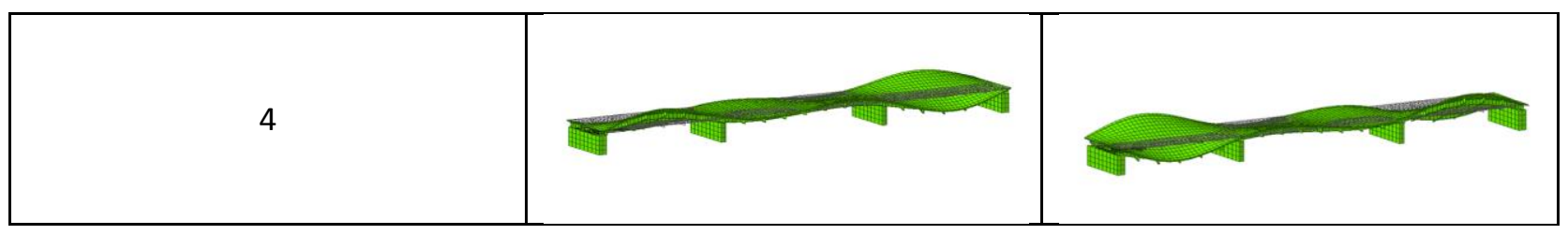

\section{CONCLUDING REMARKS}

From the dynamic testing activity carried out on the main bridges of the new BreBeMi highway, a wealth of information regarding the dynamic behaviour of composite girder flyovers was gathered; moreover, a thorough model tuning activity was carried out, and a sensitivity test on many parameters affecting the results of numerical analyses was performed, so that the FE models of the bridges implemented in MidasGen were validated against a reliable experimental benchmark and can now be used in predictive mode.

Summarizing the lessons learnt from the activity, first of all it must be remarked that the basic requirement of NTC2008, i.e. that the comparison between experimental and numerical first natural frequency is not enough to provide reliable information for model validation. For example, in both of the bridges discussed in the present paper, both for the first and for the subsequent modes, the frequencies alone could not provide a thorough identification because some of the experimentally identified frequencies were in-between two subsequent, closely spaced, numerical frequencies, so it was impossible to match either of the two adjacent numerical frequencies to the experimental data. Only by comparing the corresponding mode shapes, the identification could be completed.

Moreover, in the first part of the present paper, the effect of different analytical modelling techniques on the response of a straight and skewed composite bridge was studied, by comparing the results of three different FE models to the experimental data. It was found out that two simplified modelling approaches, named Model N.2 and Model N.3, give very similar and equally reliable results, if the elements are provided an adequate mesh discretization, whereas Model N.1 can thus be deemed accurate enough to be used in setting up an experimental test configuration but it is not adequate for validating the final response of composite bridges.

In the second part of the present paper, a manual model updating was performed by means of a sensibility study for uncertain parameters like expansion joint stiffness, inclusion of noise barriers, dynamic stiffness of rubber bearings, and connection stiffness of truss elements. The flexural and torsional mode responses of both bridges were not found to be very sensitive to the bracing connections and the rubber bearing stiffness. The resulting FE model included more realistic structural parameters and provided dynamic properties that are better matching with the experimental test response of the bridge.

In this model tuning phase, it was found out that the contribution of the expansion joints on the experimental test response is crucial: when implementing the model, it must be clarified if the expansion joints are functional in the transverse direction or not, in order to assign the correct restraints to the side elements of the bridge. In low to moderate seismic sites, many structural designers are used to designing the expansion joints only along the axis of the bridge, neglecting the transverse restraint they provide, which affects the dynamic properties under low vibrations.

Finally, the presence of sound barriers was also found out to be important in terms of additional dynamic mass to the global mass matrix of the system due to the light weight of the composite steel-concrete structure, even if their stiffness contribution was not found to be important. For slender, light bridges, the presence of additional sources of mass during the dynamic tests must thus be carefully considered in the models in order to provide good estimates for the dynamic properties.

\section{REFERENCES}

[1] NTC 2008 (2008). D.M. 14-01-2008, Nuove Norme Tecniche per le Costruzioni, in Italian.

[2] Peeters, F., Vanhollebeke, H., Van der Auweraer, H. (2005). "Operational PolyMAX for estimating the dynamic properties of a stadium structure during a football game", Proc. of Intl. Conf. IMAC XXIII, Orlando, FL, USA

[3] Peeters, B., Van der Auweraer, H., Guillaume, P., Leuridan, J. (2004). "The PolyMAX frequency-domain method: a new standard for modal parameter estimation?", Shock and Vibration, 11(3-4), IOS Press, 395-409.

[4] Cigada, A., Mola, E., Moschini, S., Paksoy, M., Pozzuoli, C., Vanali, M. (2014). 'Numerical Modelling and Dynamic Testing on the Oglio Flyover of the New BreBeMi Highway in Italy", Conference Proceedings of the Society for Experimental Mechanics Series 2014, Dynamics of Civil Structures, Volume 4, pp 381-394. 